\title{
DNA Synthesis Induction
}

National Cancer Institute

\section{Source}

National Cancer Institute. DNA Synthesis Induction. NCI Thesaurus. Code C40663.

DNA Synthesis Induction consists of the initiation of activities involved in the polymeric

linkage of deoxyribose moieties (with adenine, guanine, cytosine, or thymine side chains)

by phosphate groups attached to their 5-prime and 3-prime sugar hydroxyls. 